\title{
Indian Journal of Otolaryngology and Head and Neck Surgery
}

\section{EDITORIAL}

As we are reaching the end of the first year in office of IJOHNS, we need to look back. We feel happy and proud to bring out four issues of IJOHNS in a better format and a new look. We are proud to inform you that we could clear the entire backlog of accepted articles lying with Editorial office since 1999. This Issue contains some new articles submitted to the Hyderabad office in 2006 itself. We have reduced waiting period for publication from years to months. We could not concentrate on the quality and content of the Journal due to prior commitments and acceptance before our time.

Bringing out four issues of IJOHNS without any financial support and share from the Headquarters, is a difficult proposition. It is not out of place to mention the efforts of the previous Editor Dr.Anirban Biswas, who brought out two Special Issues and provided some financial backup, albeit, collected towards funds for IJOHNS. Thanks to the subscribers, authors and very few Advertisers, along with this backup funds, you received this year's journals. We have also indexed the two special issues which were published in 2005 to help the authors to quote their articles.

Throughout the year we received both bouquets and brickbats. Complimentary and congratulatory notes and mails poured in which increased our enthusiasm. The 'hate mail' has come down as most of the grievances are sorted out. We again reiterate that any e-mail will be responded to within 48 hours and all letters will have a reply posted within one week.

We have been receiving enquiries on a regular basis about the activities of AOI- Membership Status, Newsletter, New Membership, Election Schedule and other sundry details about AOI. Unfortunately, we have no information regarding these and the members are requested to contact the President, Secretary and the Treasurer. For obvious reasons known to everyone, we cannot comment upon this but will be submitted in the annual report which will be presented at General Body Meeting at Bhubaneshwar.

Another area of serious concern is updating our Addressograph and reducing the number of Journals being returned undelivered. Though the number is considerably reduced, but it pains us to get these Journals back for simple reasons. We request all the members to keep us informed if they have changed the address. We assure you that updating the addressograph is done as soon as we receive the letters or mail.

We have put in a stringent Review System in place so that it improves the quality and content of the Journal. This is absolutely necessary when we go for indexing the journal. The journal also lacks global presence and exposure.

The publishing also has moved out of Mumbai to Hyderabad to facilitate the functioning. As a result our Website maintained by Medknow Publications has become nonfunctional and we are not encouraging electronic submission of articles. We are trying to rectify this and launch a new website which also includes digitalized archives.

We are very glad to inform that $\mathrm{M} / \mathrm{s}$ Springer Publications, an international giant in medical publishing has shown great interest in co-publishing IJOHNS along with our Association to give much needed help in indexing and global exposure. The negotiations are at an advanced level and in all possibilities we may be able to announce the details at Bhubaneshwar.

Finally, we are here committed to improvement. This is your Journal. Your valuable suggestions, constructive criticisms and practical ideas are welcome. Let us work together to take IJOHNS to further heights and international standards.

\author{
Dr. P.S.N. Murthy \\ Chairman \\ Editorial Board, IJOHNS
}

\author{
Dr. D. Dwarakanatha Reddy \\ Editor \\ IJOHNS
}

